\title{
The impact of operating conditions on exhaust emissions from a two-wheeled urban vehicle
}

\author{
Piotr Lijewski ${ }^{1}$, Natalia Szymlet ${ }^{1,},{ }^{*}$, ukasz Rymaniak $^{1}$, Barbara Sokolnicka ${ }^{1}$, \\ and Andrzej Domowicz ${ }^{1}$ \\ ${ }^{1}$ Politechnika Poznańska, Instytut Silników Spalinowych i Transportu
}

\begin{abstract}
The subject of the article is the exhaust emission analysis of harmful gases from an two-wheeled urban motor vehicle in real operating conditions. For this purpose, characteristics of ecological indicators of compounds such as hydrocarbons ( $\mathrm{HC})$, carbon monoxide (CO), carbon dioxide $\left(\mathrm{CO}_{2}\right)$ and nitrogen oxides $\left(\mathrm{NO}_{\mathrm{x}}\right)$ were presented. The tests were carried out on a two-wheeled urban vehicle, equipped with an engine with a stroke volume of $49 \mathrm{~cm}^{3}$ and a maximum power of $2.5 \mathrm{~kW}$. What's more, the operating parameters of a moped registered during the test were also analyzed. The measurements were performed in real operating conditions in the Poznań agglomeration. The designated route included streets in the city center, and the maximum permissible speed did not exceed $50 \mathrm{~km} / \mathrm{h}$. The AXION R/S+ mobile apparatus belonging to the PEMS (Portable Emissions Measurement Systems) group was used for the research. The device is one of the most modern measuring instruments, enabling the measurement of concentrations and emissions of both gaseous and solid exhaust components. What is more, the obtained results of road emissions of harmful compounds were referred to the limit value of the exhaust emission norms, which the tested vehicle is expected to meet (Euro 3). The results indicated that the limit value for carbon monoxide was exceeded by $52 \%$.
\end{abstract}

\section{Introduction}

In accordance with the Polish traffic law of June 20, 1998, a moped is a one- or two-axle vehicle, equipped with a combustion engine with a stroke volume not exceeding $50 \mathrm{~cm}^{3}$, whose design limits its travel speed to $45 \mathrm{~km} / \mathrm{h}$. [1]. Such vehicle characteristics make it preferable for driving in urban traffic, where road vehicle users and city authorities face the problem of congestion or lack of parking spaces. Therefore, in order to limit the time and costs two-wheeled vehicles are being used more and more often, this is particularly true for mopeds. This phenomenon is visible primarily in densely populated urban agglomerations such as in India and China, where the total share of two-wheelers constitutes $70 \%$ of the entire fleet of road vehicles [2]. Extensive literature studies have shown that the most extensive research works are carried out in Asian research and development centers, aimed at assessing the emission of harmful and toxic compounds of exhaust gases from this type

* Corresponding author: natalia.r.szymlet@doctorate.put.poznan.pl 
of vehicles. These tests focus primarily on the modification of type approval tests based on the operating parameters obtained in real driving conditions [3, 4]. The lack of regulations concerning the RDE (Real Driving Emissions) procedure for two-wheeled vehicles, as well as the lack of available equipment for exhaust emission tests from this group of vehicles, resulted in them only being tested in laboratory conditions thus far.

\section{Research methodology}

\subsection{Research object}

The tests in real driving conditions were performed on a moped whose four-stroke engine was characterized by a $50 \mathrm{~cm}^{3}$ displacement volume and a power of $2.5 \mathrm{~kW}$. The vehicle was manufactured in 2013, so it is subject to the Euro 3 emission norm. The vehicle was checked for any technical defects before the test. Table 1 presents the technical data of the test vehicle, while Figure 1 shows the tested vehicle together with the measuring apparatus.

Table 1. Tested vehicle technical parameters.

\begin{tabular}{|c|c|}
\hline Engine type & SI \\
\hline Number and arrangement of cylinders, number of valves & single-cylinder, 2 valves \\
\hline Displacement & $49 \mathrm{~cm}^{3}$ \\
\hline Bore/stroke & $37,8 \mathrm{~mm} / 44 \mathrm{~mm}$ \\
\hline Maximum power & $2.5 \mathrm{~kW} / 7000 \mathrm{rpm}$ \\
\hline Maximum torque & $3.5 \mathrm{Nm} / 6750 \mathrm{rpm}$ \\
\hline Cooling & liquid \\
\hline Valve timing & ohc \\
\hline
\end{tabular}

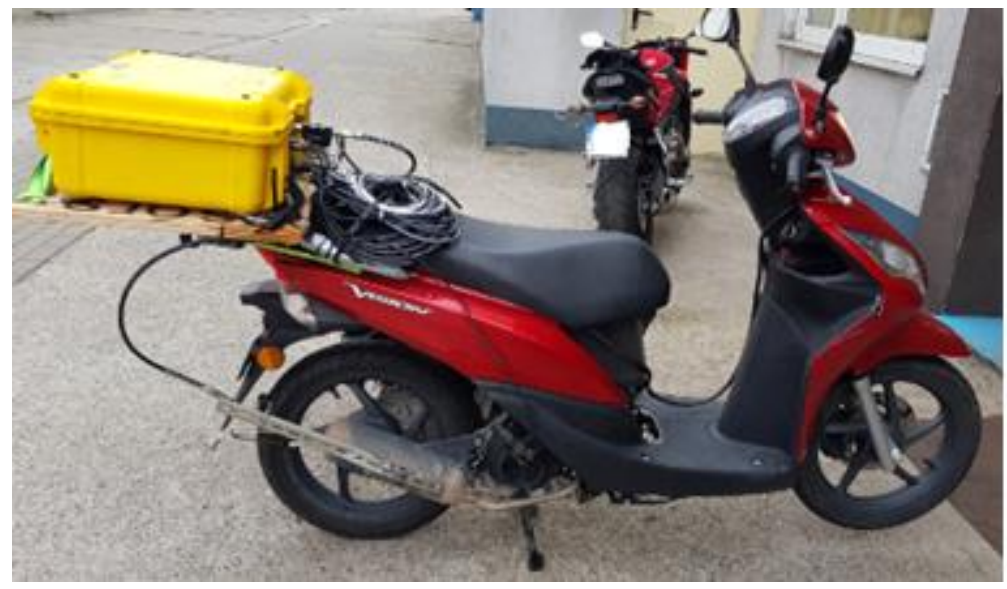

Fig. 1. Test vehicle with Axion R/S+ device. 


\subsection{Research methodology}

The equipment used for real operating conditions tests was Axion $\mathrm{R} / \mathrm{S}+$, belonging to the PEMS (Portable Emissions Measurement System) group [5-7]. The apparatus allows the measurement of both gaseous $\left(\mathrm{CO}, \mathrm{CO}_{2}, \mathrm{NO}, \mathrm{HC}\right)$ and solid $(\mathrm{PM})$ emission compounds. To determine compounds such as carbon monoxide, carbon dioxide or hydrocarbons, an NDIR (Nondispersive Infrared Sensor) analyzer was used, while an electrochemical analyzer was used to measure nitric oxide concentration. The method based on Laser Scatter was used for the measurement of solid particles. Figure 2 presents the Axion R/S+ measuring apparatus.

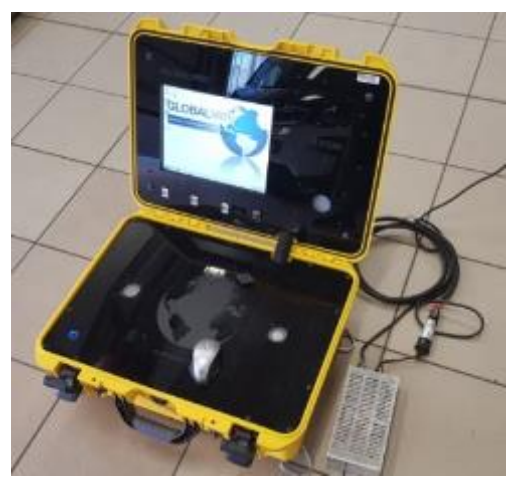

Fig. 2. The AxionR/S+ device.

Axion R/S+ was equipped with a meteorological station, a GPS as well as a module enabling registration of data from the on-board diagnostic system - OBD. The device measured and acquired data at a frequency of $1 \mathrm{~Hz}$. Based on the recorded data, corrections were made to the obtained results, and then the road/specific exhaust emission values from the test were calculated [8].

In the aspect of exhaust emissions testing from two-wheeled vehicles in actual conditions of operation, this apparatus provides unparalleled flexibility and ease of use. Its small size and weight (only $18 \mathrm{~kg}$ ), allow measuring the emissions in real driving conditions even with the smallest two-wheeled vehicles. Considering the fact that this measuring device has become available for purchase worldwide only recently, this publication is one of the first research works on the subject of pollutant and toxic compounds emission tests of two-wheeled vehicles in real operating conditions. Researchers from Austria [9] measured the emissions of gaseous compounds from a vehicle in real conditions for a larger motorcycle, however, this was done using equipment dedicated to passenger cars, which excludes measurements of emissions from urban twowheeled vehicles.

\subsection{Test route}

The test route was the city center of the Poznan agglomeration. The aim of the research was to determine the real emission from two-wheeled vehicles in real conditions of their operation. Based on their design and construction, mopeds are adapted for urban driving, hence the route included only roads with a maximum speed of up to $50 \mathrm{~km} / \mathrm{h}$. The route started at the Poznan University of Technology, which greatly facilitated the research 
process, and its total length was $7.1 \mathrm{~km}$. The route, determined on the basis of data obtained from GPS, is shown in Figure 3.

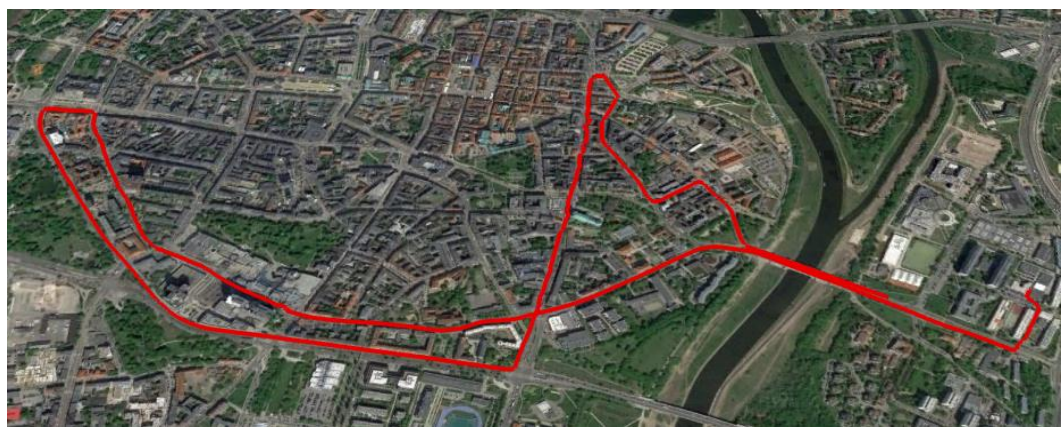

Fig. 3. The test toure used for the drive cycle [10].

\section{Analysis and results}

\subsection{Analysis of engine operating conditions}

The data obtained during the moped tests in real operating conditions allowed to obtain the engine operation time density characteristics, which are a graphical representation of the share of engine operating time (compared to the duration of the whole test) for individual vehicle speed and acceleration ranges. The characteristic showed that the vehicle most often worked at a speed of $0 \mathrm{~km} / \mathrm{h}$ and at accelerations in the range of $-0.5-0 \mathrm{~m} / \mathrm{s}^{2}$, i.e. idling. The share of operating time in this area amounted to $24 \%$ (Figure 4), which results from the characteristics of urban traffic (road congestion, a large number of traffic lights). A significant share of operating time was also found for the speed range of $10-30 \mathrm{~km} / \mathrm{h}$ and accelerations of $0-1 \mathrm{~m} / \mathrm{s}^{2}$, which amounted to $21 \%$ in total. This is confirmed by the average vehicle speed and acceleration values of $21 \mathrm{~km} / \mathrm{h}$ and $0.57 \mathrm{~m} / \mathrm{s}^{2}$, respectively.

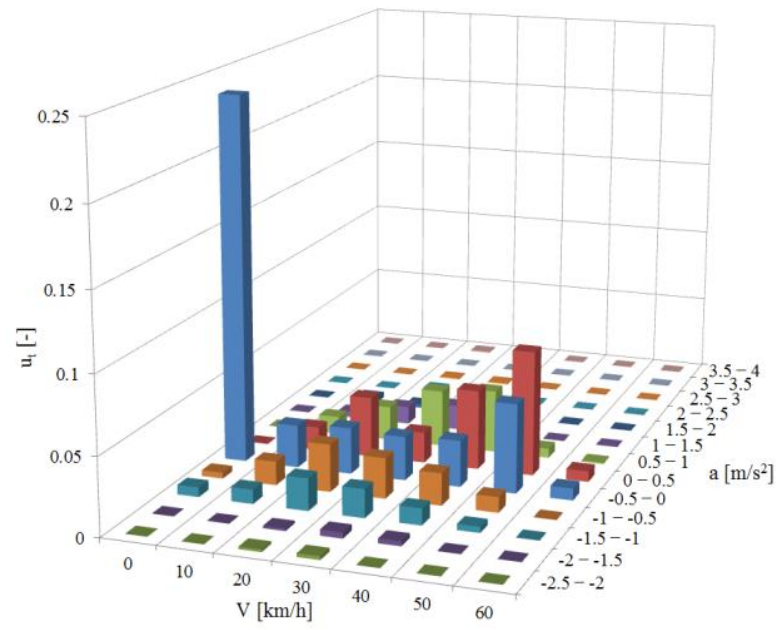

Fig. 4. Time density characteristics of the tested vehicle driving in real operating conditions. 


\subsection{Analysis of the engine ecological indicators}

The environmental performance characteristics for the tested vehicle were also presented in the function of individual vehicle speed and acceleration ranges, as was the case with the engine time density characteristics. The impact of these vehicle performance parameters on emissions has been assessed for each toxic exhaust component $\left(\mathrm{HC}, \mathrm{CO}, \mathrm{NO}_{\mathrm{x}}\right)$ limited under Euro 3 norm as well as for the harmful $\mathrm{CO}_{2}$ which is not limited by the emission norms.

$\mathrm{CO}_{2}$ emissions as a function of time depend on both vehicle speed and acceleration (Figure 5a). An even distribution of carbon dioxide emission values was recorded in all acceleration ranges. However, the maximum value of carbon dioxide emissions $(0.52 \mathrm{~g} / \mathrm{s})$ for the tested moped was recorded for the speed range of $20-30 \mathrm{~km} / \mathrm{h}$ and accelerations of $2.5-3 \mathrm{~m} / \mathrm{s}^{2}$, i.e. in the range of medium speeds and high accelerations. The average emission for this compound was $0.23 \mathrm{~g} / \mathrm{s}$.

a)

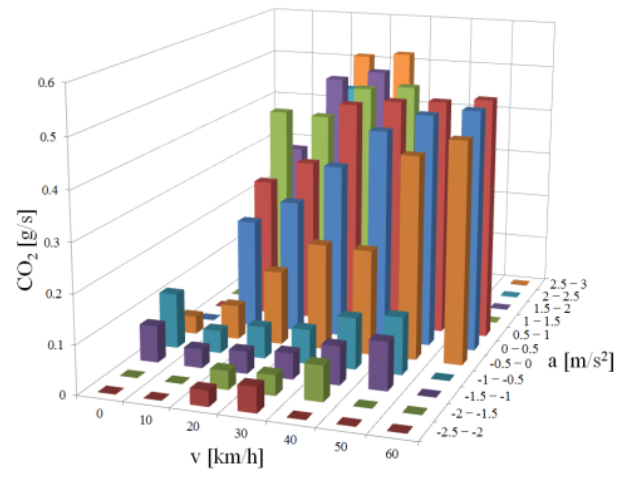

b)

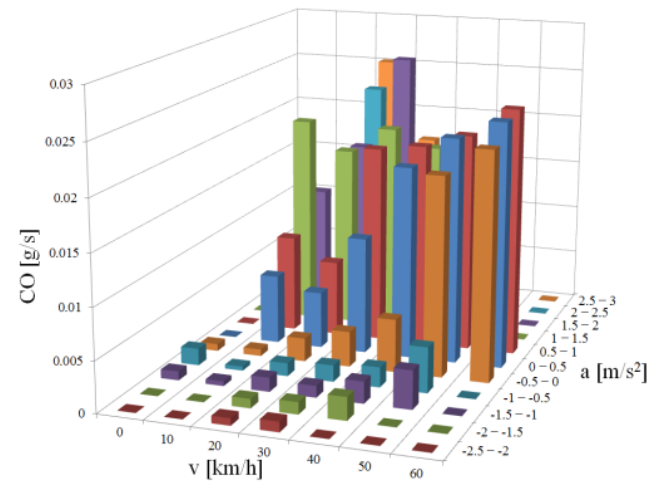

Fig. 5. Emission value per second as a function of vehicle speed and accelerations intervals for a) $\mathrm{CO}_{2}$, b) $\mathrm{CO}$.

The characteristics of the per second carbon monoxide emission as a function of vehicle speed and accelerations (Fig. 5b) showed that the highest emission values of this compound were in the ranges of medium speeds and high accelerations $\left(10-30 \mathrm{~km} / \mathrm{h}\right.$ and $\left.1-2 \mathrm{~m} / \mathrm{s}^{2}\right)$. High engine loads favor global and local oxygen deficiency, which is closely related to the formation of carbon monoxide. In addition, a high temperature in the cylinder also contributes to the formation $\mathrm{CO}$ through the decomposition of $\mathrm{CO}_{2}$. The highest emission value, $0.027 \mathrm{~g} / \mathrm{s}$, was recorded for speeds in the range of $20-30 \mathrm{~km} / \mathrm{h}$ and accelerations of $1.5-2 \mathrm{~m} / \mathrm{s}^{2}$.

The characteristics of hydrocarbon emissions as a function of vehicle speed and accelerations are shown in Figure 6a. The obtained data indicates that the highest emission values were in the area of medium speeds in the range of $10-30 \mathrm{~km} / \mathrm{h}$ and accelerations in the range of $1-2.5 \mathrm{~m} / \mathrm{s}^{2}$. For such load values, the engine operates in transient states, subjected to inertia resistances, resulting in temporary enrichment of the fuel-air mixture, which is a factor favoring the formation of hydrocarbons. The highest value, $0.004 \mathrm{~g} / \mathrm{s}$, was recorded for speeds in the range of $10-20 \mathrm{~km} / \mathrm{h}$ and accelerations of $1.5-2 \mathrm{~m} / \mathrm{s}^{2}$.

Analysis of the nitrogen oxides ecological indicators characteristics showed that the largest share in the total emission can be found the high engine speed ranges ranging between $50-60 \mathrm{~km} / \mathrm{h}$ and medium accelerations of $0-1.5 \mathrm{~m} / \mathrm{s}^{2}$ (Fig. $6 \mathrm{~b}$ ). The highest value, $0.0021 \mathrm{~g} / \mathrm{s}$, was recorded for vehicle speed range $50-60 \mathrm{~km} / \mathrm{h}$ and acceleration in the range $0.5-1 \mathrm{~m} / \mathrm{s}^{2}$, while the average emission value of this compound was $0.00081 \mathrm{~g} / \mathrm{s}$. The high 
speed of the vehicle generates a higher temperature in the cylinders, which directly promotes the formation of nitrogen oxides. Such a high vehicle speed value for a moped $(>50 \mathrm{~km} / \mathrm{h}$ ) results from the local terrain features, which lead to rolling downhill.

a)

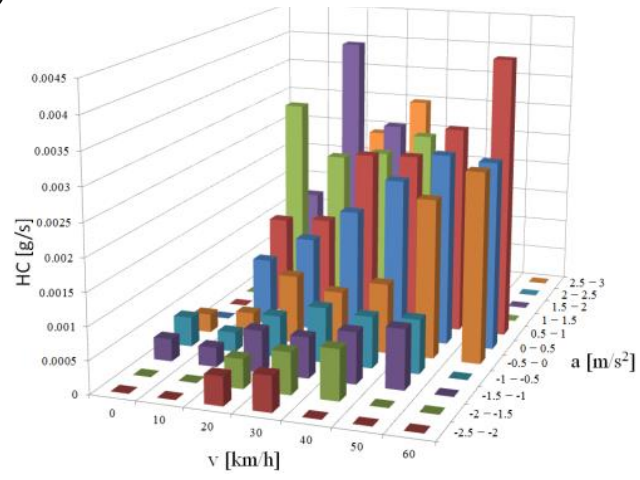

b)

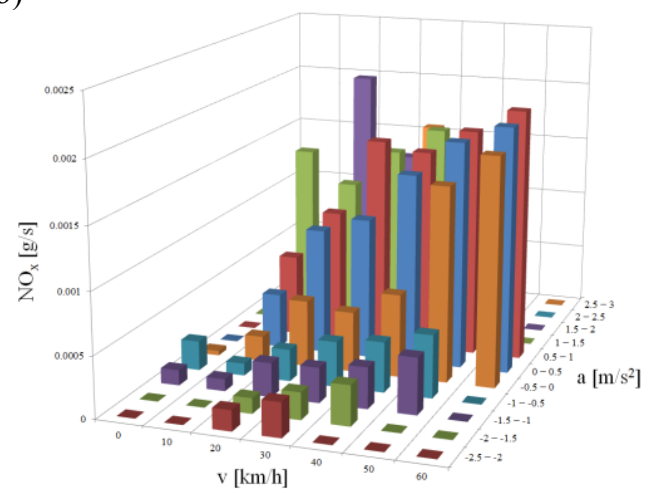

Fig. 6. Emission per second value as a function of vehicle speed and acceleration ranges for a) HC, b) $\mathrm{NO}_{\mathrm{x}}$.

The road emission values of all exhaust components limited by the Euro 3 norm have been referred to the limit values of the said norm and carbon monoxide emissions have exceeded the norm by 52\% (Figure 7). This phenomenon results from more diversified engine operating conditions under real operating conditions than in the case of a type approval tests, where the engine loads are limited. For the test in real conditions, therefore, we have an engine load characteristic, and not a full engine power characteristic as in the case of a laboratory test.

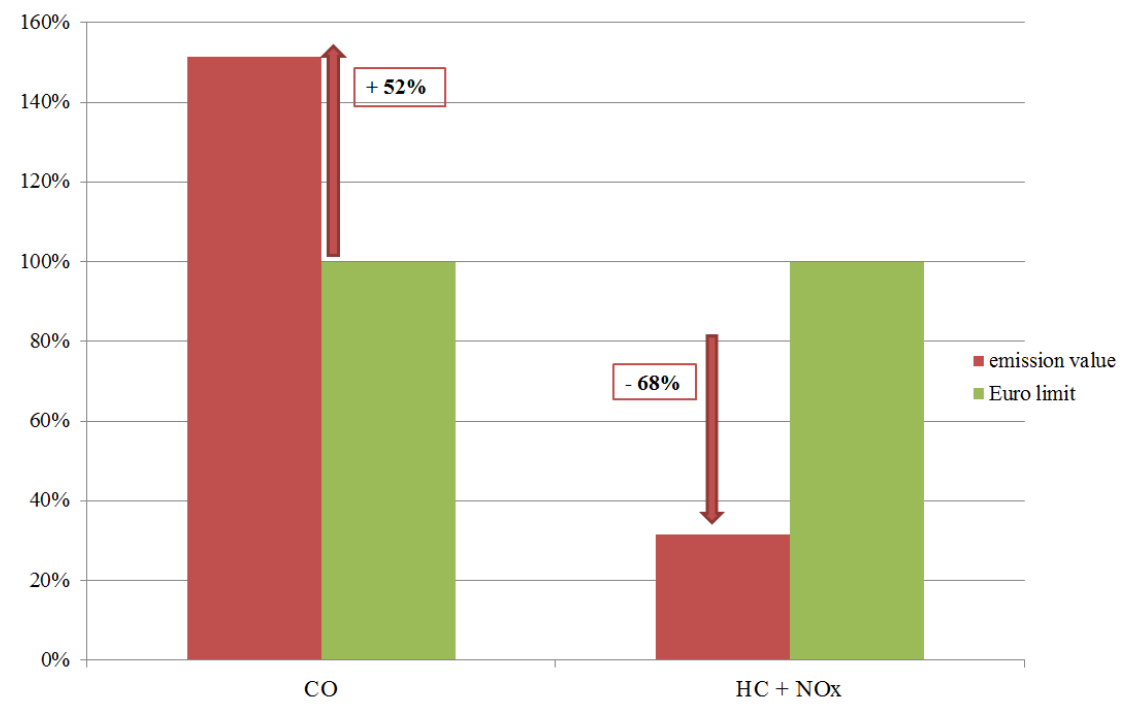

Fig. 7. Comparison of the exhaust emission results with the Euro 3 norm limits. 


\section{Conclusions}

The vehicle group to which the tested vehicle belonged is characterized by a relatively simple construction (simplified power systems, limited number of electronic systems), which results in the users of such two-wheeled vehicles often making slight adjustments or repairs by themselves, rather than at authorized service centers. In part because of this these vehicles are characterized by significant emission factors, primarily hydrocarbons and carbon monoxide, as shown in this article. The continuous population increase, and hence also the number of vehicles used (including two-wheeled vehicles), means that inhabitants of densely populated cities are particularly exposed to threats resulting from the environmentally harmful operation of two-wheeled vehicles.

What's more, exceeding the emission limit values specified in the Euro 3 norm results from the more diversified operating conditions that occur in the case of actual vehicle operation. Many scientific and research works have shown significant differences in the results of exhaust emission tests performed in laboratory conditions and in real operating conditions [11]. This fact confirms the legitimacy of conducting emission tests in real driving conditions for this group of vehicles, because only this method can provide full and reliable results.

\section{References}

1. Ustawa z dnia 20 czerwca 1997 r. - Prawo o ruchu drogowym

2. J. H. Tsai, P. H. Hunag, H. L. Chiang, Atm. Env. 153, 126-134 (2017)

3. H. Y. Tong, H. D. Tung, W. T. Nguyen, Atm. Env. 45, 5191-5199 (2011)

4. J. H. Tsai, H. L. Chiang, Y. C. Hsu, B. J. Peng, R. F. Hung, Atm. Env. 39, 6631-6641 (2005)

5. J. Merkisz, P. Lijewski, P. Fuć, M. Siedlecki, Appl. Eng. In Agr. 31, 875-879 (2015)

6. J. Merkisz, P. Lijewski, P. Fuć, S. Weymann, Ekspl.i Niez. 15, 364-368 (2013)

7. J. Merkisz, J. Pielecha, P. Fuć, P. Lijewski, VPPC, 903-907 (2013)

8. www. globalmrv.com

9. J. Hiesmayr, S. Schmidt, S. Hausberger, R. Kirchberger, C. Zinner, P. Filips, R. Wanker, H. Friedl, JSAE 32 (2017)

10. www.gpsvisualizer.com

11. W. Saleh, R. Kumar, H. Kirby, P. Kumar, Trans. Research 14, 326-333 (2009) 